\title{
Effect of Laser Gas Nitriding on the Microstructure and Corrosion Properties of Ti-6AI-4V Alloy
}

\author{
Reza Shoja RAZAVI, ${ }^{1)}$ Mehdi SALEHI, ${ }^{1)}$ Mahmood MONIRVAGHEFI" and Reza MOZAFARINIA ${ }^{2)}$ \\ 1) Materials Engineering Department, Isfahan University of Technology, Isfahan, Iran. E-mail: p8130087@sepahan.iut.ac.ir, \\ isrec@cc.iut.ac.ir, vagh_mah@cc.iut.ac.ir 2) Materials Engineering Department, Malek Ashtar University of Technology, \\ Shahin-shahr, Iran. E-mail: mozafar_r@mut-esf.ac.ir
}

(Received on September 27, 2006; accepted on February 14, 2007)

\begin{abstract}
Laser surface melting of Ti-6Al-4V alloy under a pure nitrogen environment of $30 \mathrm{~L} / \mathrm{min}$ gas flow rate, was carried out with 200-600 mJ laser beams, produced by a Nd-YAG pulsed laser at $5 \mathrm{~mm}$ defocused distance, and $0.5-3 \mathrm{~mm} / \mathrm{s}$ sample traverse velocities. The microstructure, hardness and corrosion behaviour of the nitrided samples were examined, using scanning electron microscopy, X-ray diffractometry (XRD), microhardness measurements across the workpiece cross-section and anodic polarization tests in $2 \mathrm{M} \mathrm{HCl} \mathrm{so-}$ lution.

The microstructures consisted mainly of a thin continuous layer of titanium nitride followed by nearly perpendicular dendrites, and below this, a mixture of small dendrites and large needles, which had a random orientation. The denderitic structure was the TiN phase, and the needle phase and the phase of the matrix between the dendrites were nitrogen-enriched $\alpha^{\prime}-\mathrm{Ti}$. The density of TiN dendrites decreased gradually towards the interface between the nitrided layer and the substrate. The melted zone showed a range of hardness of between $400-1300 \mathrm{Hv}$, the hardness being found to be related to the dendrite populations. An improvement in corrosion behaviour, associated with the presence of a good TiN coating, was observed. Also, the improved pitting corrosion resistance is obtained due to the microstructural changes after laser treatment.
\end{abstract}

KEY WORDS: laser nitriding; Ti-6AI-4V; microstructure and corrosion.

\section{Introduction}

Ti-6Al-4V alloy finds wide application in industry due to its high strength-to-weight ratio and excellent corrosion resistance. However, the alloy suffers from low wear resistance, which prevents it from being widely applied as engineering tribological components. ${ }^{1)}$ One of the most efficient means to improve the tribolagical properties of the alloy is laser gas alloying. Laser nitriding of Ti-6Al-4V alloys has been investigated extensively in recent year with the aim of improving the material surface properties, especially the hardness, the wear resistance and the corrosion resistance. $^{2-20)}$ A wide research area has been explored in the processing, which includes the improvement of the surface properties, the analysis of the residual stress and cracking induced in the material, the melt-pool depth and profile developed by the beam, and the microstructural characterization. The hardness was reported to reach $2000 \mathrm{Hv}$ in the surface hardness and the fine denderitic structure of the TiN layer contribute to the significantly enhanced cavitation erosion performances. ${ }^{10)}$ The wear resistance significantly increased. This is attributed to the increased hardness as well as the formation of wear-resistant compound in laser nitriding. ${ }^{4-7)}$ The residual stress was reduced and cracking eliminated when a dilute nitrogen environment was used for the processing. ${ }^{16)}$ All of these aspects have shown promising results and a great potential for the application of this process into industry.

However, these literatures were mainly concentrated on the microstructure and the wear behaviour of the laser gas nitrided Ti-6Al-4V alloy. Although a few studies have investigated the corrosion behaviour of $\mathrm{Ti}-6 \mathrm{Al}-4 \mathrm{~V}$ alloy that have been treated by lasers, ${ }^{17-20}$ ) very few of them have used Nd:YAG pulsed laser. In fact, using Nd:YAG pulsed laser surface treatment to improve the hardness and the corrosion resistance of $\mathrm{Ti}-6 \mathrm{Al}-4 \mathrm{~V}$ alloy, is a relatively new research area. Previous work using $\mathrm{CW} \mathrm{CO}_{2}$ and Excimer lasers has shown that, in general, laser surface treatment could enhance the corrosion resistance of Ti-6Al-4V alloy. It is envisaged that by using Nd:YAG pulsed laser surface treatment further improvement could be attained. This potential stems from the high absorbability of $1064 \mathrm{~nm}$ wavelength laser radiation by $\mathrm{Ti}-6 \mathrm{Al}-4 \mathrm{~V}$ and the short pulse duration of Nd:YAG laser, which results in extremely fast cooling rates and hence a much refined and homogenized microstructure. In the present study Nd:YAG pulsed laser surface alloying with gaseous nitrogen is employed to improve hardness and corrosion properties of $\mathrm{Ti}-6 \mathrm{Al}-4 \mathrm{~V}$ alloy. The microstructure of the laser nitrided layer is characterized and the corrosion properties are discussed through the results of potentiodynamic and cyclic polarization tests. 
Table 1. Detail of laser nitriding process conditions.

\begin{tabular}{|c|c|c|c|c|}
\hline Sample No. & $\begin{array}{c}\text { Laser Power } \\
\text { (mJ) }\end{array}$ & $\begin{array}{c}\text { Traverse Velocity } \\
(\mathrm{mm} / \mathrm{sec})\end{array}$ & $\begin{array}{c}\text { Gas Flow } \\
\text { Rate (1/min) }\end{array}$ & $\begin{array}{l}\text { DFD } \\
(\mathrm{mm})\end{array}$ \\
\hline 1 & 200 & 0.5 & 30 & 5 \\
\hline 2 & 200 & 1.5 & 30 & 5 \\
\hline 3 & 200 & 3 & 30 & 5 \\
\hline 4 & 300 & 0.5 & 30 & 5 \\
\hline 5 & 300 & 1.5 & 30 & 5 \\
\hline 6 & 300 & 3 & 30 & 5 \\
\hline 7 & 400 & 0.5 & 30 & 5 \\
\hline 8 & 400 & 1.5 & 30 & 5 \\
\hline 9 & 400 & 3 & 30 & 5 \\
\hline 10 & 500 & 0.5 & 30 & 5 \\
\hline 11 & 500 & 1.5 & 30 & 5 \\
\hline 12 & 500 & 3 & 30 & 5 \\
\hline 13 & 600 & 0.5 & 30 & 5 \\
\hline 14 & 600 & 1.5 & 30 & 5 \\
\hline 15 & 600 & 3 & 30 & 5 \\
\hline
\end{tabular}

\section{Experimental Procedure}

A Ti-6Al-4V alloy consisting of $\alpha$ and $\beta$ phase was used as the work piece material. The composition of the alloy in $\mathrm{wt} \%$ is $6 \mathrm{Al}, 4 \mathrm{~V}, 0.03 \mathrm{Cu}, 0.01 \mathrm{Cr}, 0.32 \mathrm{Fe}, 0.2 \mathrm{O}$ and balanced $\mathrm{Ti}$. The workpieces were prepared from rectangular dimension of $50 \times 50 \times 5 \mathrm{~mm}$. They were ground with 500 grit paper, polished with $1 \mu \mathrm{m}$ diamond paste and cleaned with methanol before the nitriding. Laser surface treatment was carried out using an Nd:YAG pulsed laser, which was operated at a wavelength of $1064 \mathrm{~nm}$. The laser focused spot size was $500 \mu \mathrm{m}$ diameters; pulse duration and repetition frequency were fixed at $200 \mu$ s and $10 \mathrm{~Hz}$, respectively. During the treatments, the specimens were moved in front of the laser on a work table with the surface to be treated at a defocused distance (DFD) of $5 \mathrm{~mm}$. The laser power was set between 200-600 mJ, the specimen speed between $0.5-3 \mathrm{~mm} / \mathrm{s}$. And a $50 \%$ track overlap condition was used. During laser surface treatment pure nitrogen gas was flown directly onto the laser spot point on the surface of specimen at a flow rate of $30 \mathrm{~L} / \mathrm{min}$. More details of processing conditions are listed in Table $\mathbf{1}$ and Nd:YAG pulsed laser gas nitriding setup is shown in Fig. 1.

After the laser treatment process, the workpieces were ultrasonically cleaned in chemical solvent, the track cross sections were prepared by mounting the samples in bakelite and polishing by standard metallographic techniques. The polished samples were etched chemically in a solution of $10 \mathrm{~cm}^{3}$ of hydrofluoric acid, $30 \mathrm{~cm}^{3}$ of nitric acid and $50 \mathrm{~cm}^{3}$ of water for a period of $5 \mathrm{~s}$. A Philips XL30 Scanning electron microscope was used for detailed metallographic studies. The microhardness measurements were carried out with a Zwick's, GL. microhardness tester using a $100 \mathrm{gf}$ load on metallographically polished and lightlyetched track section. Rigaku Rotoflux, RV200B equipment

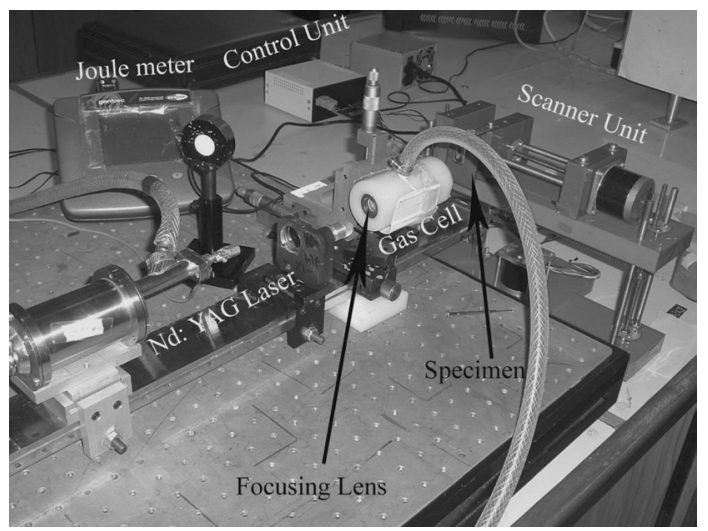

Fig. 1. Nd:YAG pulsed laser gas nitriding setup.

was used for the XRD study and the voltage-current settings of the equipment were $40 \mathrm{kV}$ and $30 \mathrm{~mA}$ using a cu$\mathrm{k} \alpha$ radiation.

Corrosion properties were evaluated by means of electrochemical techniques such as potentiodynamic and cyclic polarization curves. Testing was carried out in $2 \mathrm{M} \mathrm{HCl} \mathrm{so-}$ lution prepared from chemically pure reagents and deionized water. Electrochemical measurements were performed at $25^{\circ} \mathrm{C}$ in aerated conditions. To avoid crevice corrosion, a protective tape was used to mask the samples, allowing $1 \mathrm{~mm}^{2}$ of their surface to be in contact with the solution. Specimens were held immersed in the solution for $60 \mathrm{~min}$ before testing. The electrochemical experiment were performed using an EG\&G PARC model 273A potentiostatgalvanostat with M352 software. A saturated calomel electrode (SCE) was employed as the reference electrode and two parallel cylindrical graphite rods served as counter electrodes for current measurement. Anodic polarization curves were recorded between $300 \mathrm{mV}$ below and $1600 \mathrm{mV}$ 
over the corrosion potential $\left(E_{\text {corr }}\right)$ at $1 \mathrm{mV} / \mathrm{s}$.

\section{Results and Discussion}

\subsection{Surface Condition}

The external appearance of the top surface of the laser nitrited specimens was found to have a yellow-gold colour with a varied intensity both to the naked eye and also under the optical microscope. The golden colour is attributed to the formation of titanium nitride. ${ }^{21,22)}$ After laser treatment, samples showed a relative flat surface with no problems of adherence, crack or delamination of the alloyed tracks when the laser parameters are chosen correctly. Figure 2 shows the surface appearance of laser gas nitrided workpice (sample 11).

\subsection{Microstructure of Laser Gas Nitrided Specimens}

Laser nitriding produced denderitic structures under all processing conditions. These microstructures can be divided into three regions, zones $\mathrm{A}, \mathrm{B}$, and $\mathrm{C}$, laser melted region, heat affected zone, and Ti-6Al-4V base metal, respectively, as shown in Fig. 3. Microstructure of laser melted zone consisted of a thin continuous layer followed by a nearly perpendicular growth of dendrites, as shown in Fig. 4. Below this, a mixture of small dendrites and large needles, which had a random orientation, was produced (zone A in Fig. 3).

The amount of nitrogen is believed to have influenced the

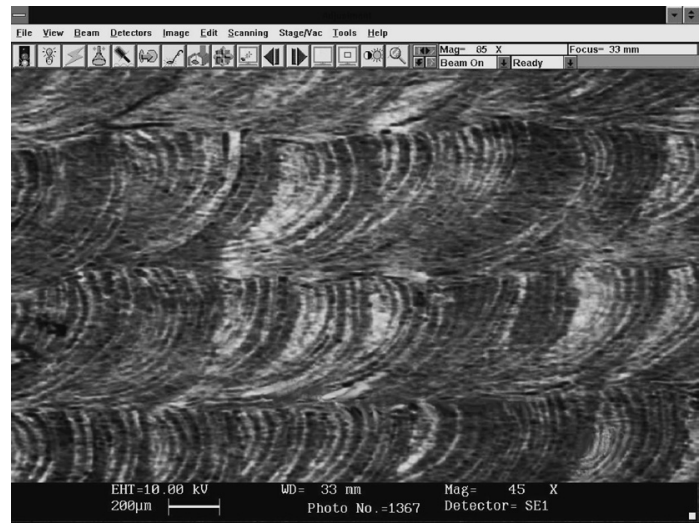

Fig. 2. Surface appearance of laser gas nitrided workpice.

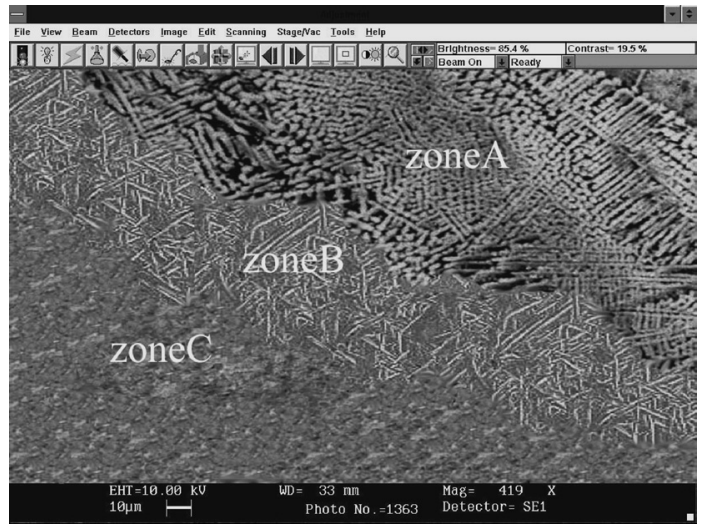

Fig. 3. Cross-section microstructure of laser gas nitrided specimens. (Zones A, B and C are laser melted zone, heat affected zone and base material, respectively.) growth of dendrites and their concentration in the melted zone. After laser treatment a high rate in solidification stage of the material and a high concentration of nitrogen on the liquid surface would be expected. Although the temperature at the surface was the highest in the melt, the liquid at the surface could have the highest undercooling, because of the high concentration of nitrogen in the surface. Temperature at the surface was below the melting point of TiN; therefore, solidification could occur from the surface, with the formation of titanium nitrides, when most of the melt pool was still in the liquid state. Moreover, a high and negative temperature gradient in the liquid ahead of that in which TiN particles had already formed, encouraged the particles to grow in the direction of the maximum undercooling, i.e. perpendicular to the surface, and resulted finally in the formation of the titanium nitride columnar dendrites. When a nitride layer is formed, nitrogen should diffuse through the layer for the nitriding process to continue. Therefore, the titanium nitride constitutes a diffusion barrier for nitrogen relatively to the metallic titanium.

Below the top surface layer, there was a layer containing a mixture of the TiN particles and some needle particles, together with a matrix of a martensitic phase of the base alloy. An X-ray spectrum from the surface, as shown in Fig. 5, confirmed that the titanium which forms in the top layer was TiN. A small amount of $\mathrm{TiN}_{0.3}$ (Peaks $\mathrm{b}$ in spectrum of Fig. 5) was also existed.

Beneath the melted and resolidified region was the heat affected zone, which was transformed to a martensitic phase, and the unaffected base material (zone B and $\mathrm{C}$ in Fig. 3).

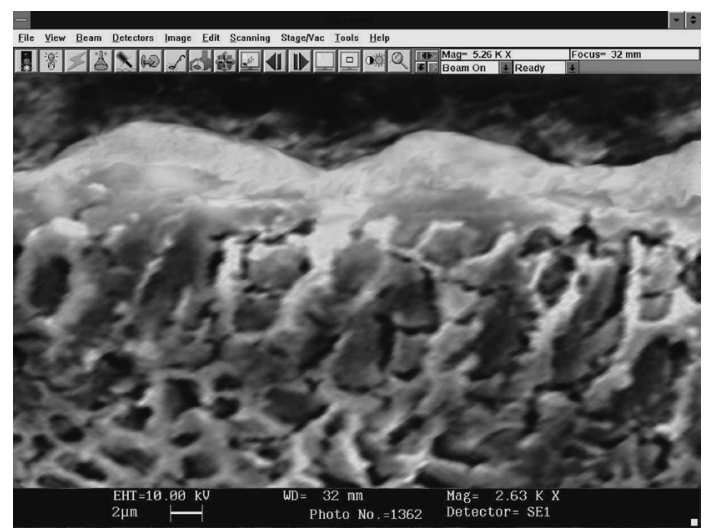

Fig. 4. Microstructure of laser melted zone consisted of a thin continuous layer followed by a nearly perpendicular growth of dendrites.

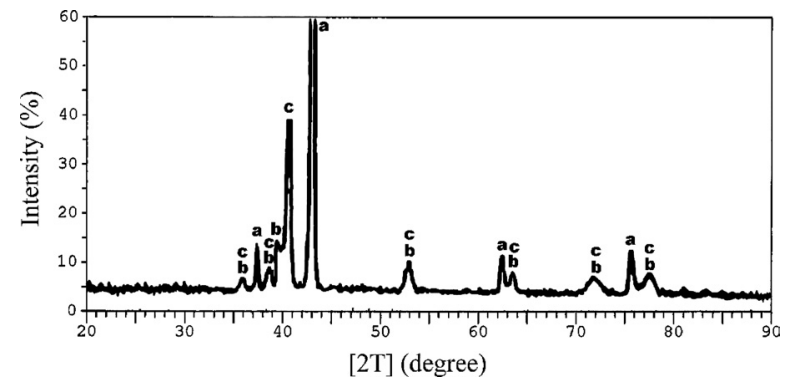

Fig. 5. XRD spectrum from the surface of laser nitrided specimen (a: TiN, b: $\left.\operatorname{TiN}_{0,3}, \mathrm{c}: \alpha^{\prime}-\mathrm{Ti}\right)$. 


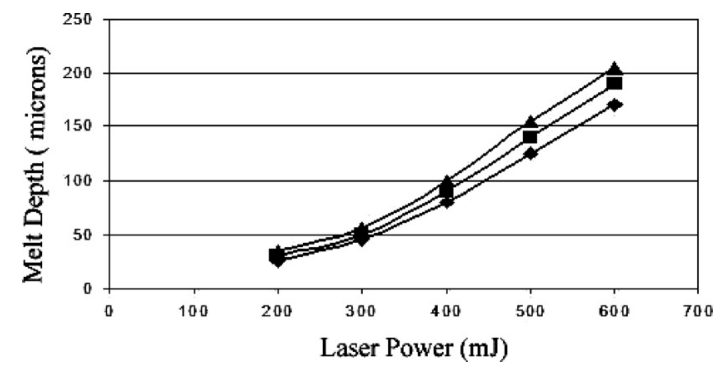

Fig. 6. Effect of travel speed and laser power on the laser melt depth (traverse velocity: $0.5 \boldsymbol{\Delta}, 1.5 \mathbf{\square}$ and $3 \diamond ; \mathrm{mm} / \mathrm{s}$ ).

\subsection{Effect of Laser Processing Parameters on Mi- crostructure}

The depth of the laser melted zone and the densities of dendrites in the region depend on the laser processing conditions. But, it was observed that, in general, the density and the size of the TiN dendrites in the nitride surface layer gradually decreased toward the interface between the nitrided layer and the substrate, as shown in Fig. 3, which simultaneously reveals the reduced density and size of the TiN dendrites. Figure 6 shows the effect of travel speed and laser power on the melt depth for the three sets of parameters. It can be seen that the melt depth differs significantly between melted zone produced by the three sets of parameters due to the difference in travel speed. Again with in each set of parameter, melt depth increased with an increase in energy input. These data can be used as guidelines for selecting parameters to achieve specific remelt depth.

The volume concentration and also the sizes of the dendrites were found to increase with increasing laser power (Fig. 7). Again, the micrographs of the melted zones in Fig. 7 show that the size and the volume of the dendrites decreasing at the higher velocity. Fig. 7(b) also, shows that at a laser power of $500 \mathrm{~mJ}$ cracking was absent, but it increased significantly with laser powers above this value. The present work, particularly, illustrated by the track produced with a $600 \mathrm{~mJ}$ laser power, showed some vertical cracks passing through the melt depth (Fig. 7(c)).

Laser nitriding at a high velocity or a low laser energy density reduced the availability of nitrogen for dissolution in the melt, and hence, fewer nitride nucleation sites were believed to be present. For this reason fewer TiN dendrites were found in tracks produced at higher velocities and lower energy densities. In a melt produced by a high laser power at low velocity, numerous dendrite nucleation sites were considered to be present and more dendrites were produced. However, an increased number of nuclei were believed to have led to less dendrite growth, resulting in a random orientation of the dendrites in the TiN-dense region. In fact, with decreasing traverse velocity and increasing energy density, the interaction time between the melt and the nitrogen gas is prolonged, and consequently, the amount of nitrogen pick-up, resulted in a higher concentration of dendrites. Therefore the growth and orientation of the dendrites, their sizes and densities are related to head intensities and traverse velocities.

Cracking along the track length (Fig. 7(c)) is considered to be associated with the residual stress field in the solidified zone. The reduced crack intensity with decreasing laser powers may be related to the formation of fewer TiN den-
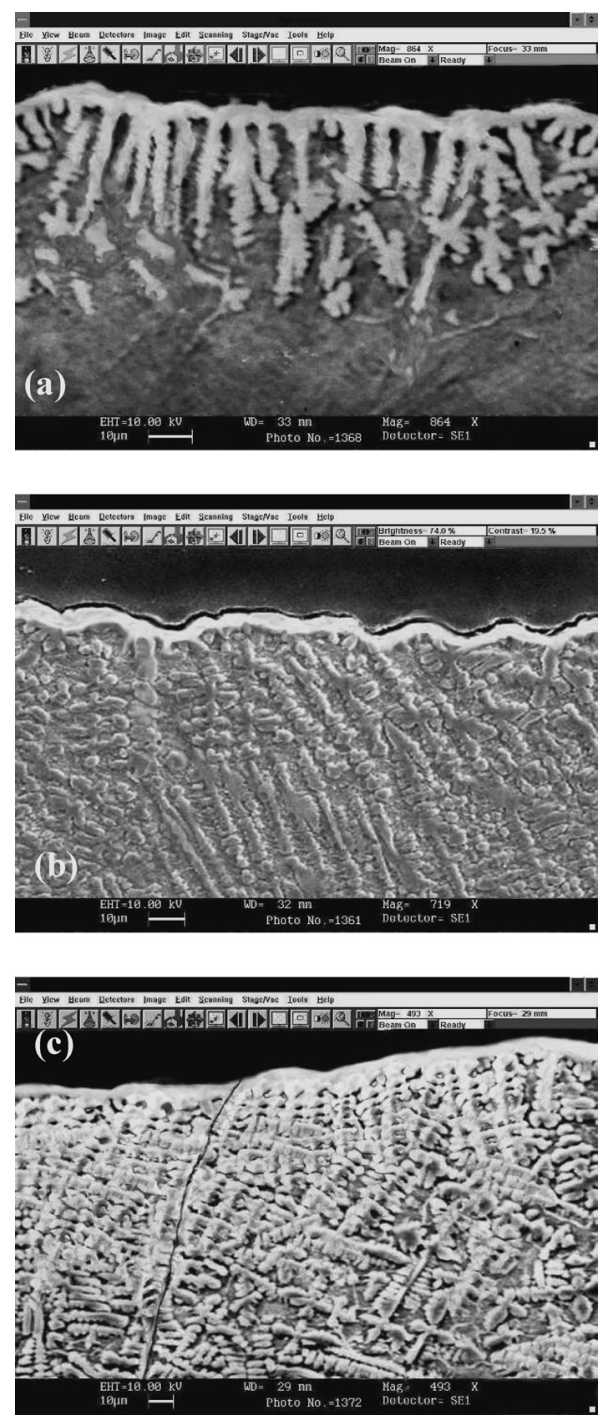

Fig. 7. Effect of laser power on the microstructure of melted zone (a: sample 6, b: sample 11 and c: sample 13).

drites. The smaller heat input with higher velocity, reduces the amount of dendrite formation in the melted layer and, hence, reduces residual stresses. From these observations it appears that an optimum dendrite population and size distribution is required, below which cracking can be avoided. In the present study, these optimum conditions produced with a $500 \mathrm{~mJ}$ laser power and $1.5 \mathrm{~mm} / \mathrm{s}$ traverse velocity (sample 11).

\subsection{Hardness Profiles}

The harnesses are plotted against melt depths in Fig. 8, the graphs indicating that a lower hardness was developed in the nitrided layer using lower laser powers and higher glazing velocities. Low laser energy density and high specimen velocity, actually, decreased the concentration of TiN dendrites in the melt. the maximum hardness developed, was about $1300 \mathrm{Hv}$ for tracks produced with a $600 \mathrm{~mJ}$ laser power and $0.5 \mathrm{~mm} / \mathrm{s}$ velocity, which is over three time higher than the base hardness $(400 \mathrm{Hv})$; whilst the $300 \mathrm{~mJ}$ laser power and $3 \mathrm{~mm} / \mathrm{s}$ velocity tracks developed a surface hardness of about $700 \mathrm{Hv}$. The dense TiN dendrite regions in the melted zones produced a greater hardness compared to other regions with lower concentration of dendrites. Only 


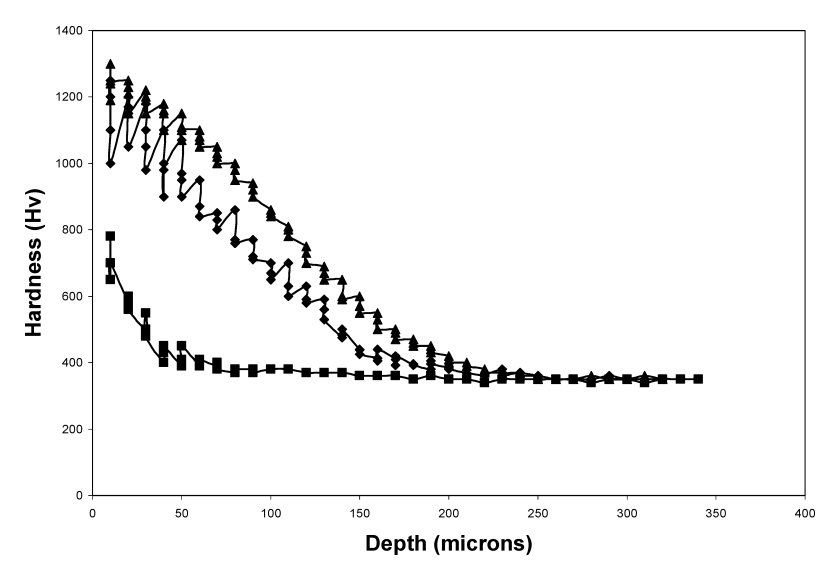

Fig. 8. Hardness profile in laser nitrided specimens ( $\boldsymbol{\Delta}$ : sample 13, $\diamond$ : sample 11 and $\mathbf{\square}$ : sample 6).

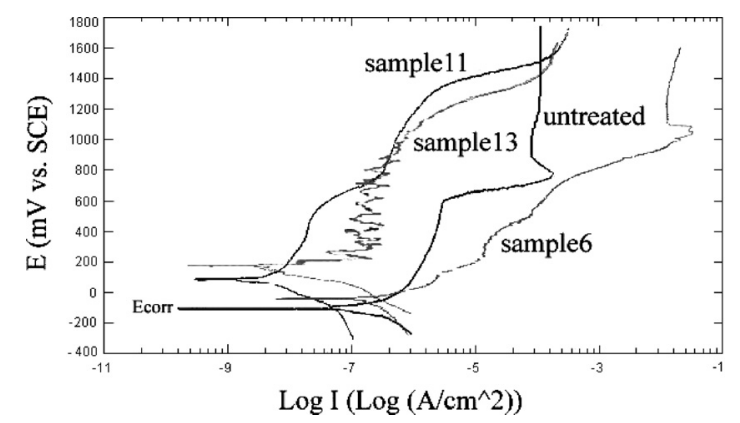

Fig. 9. Potentiodynamic polarization curves for the untreated and laser treated specimens.

a small increase in hardness was obtained in regions where no TiN dendrites were observed. Therefore the hardness was, presumably, related to the TiN concentration.

\subsection{Corrosion Properties}

\subsubsection{Potentiodynamic Polarization}

Figure 9 shows the potentiodynamic polarization curves for the untreated and laser treated specimens. In general, the corrosion potential of laser gas nitrided specimens was relatively more noble than the untreated sample and lied in the rang of -50 to $+200 \mathrm{mV} v s$. SCE for different samples. This is mainly due to the fact that TiN is more noble than titanium. Furthermore, the proper laser treated specimen (sample 11) also had a very small corrosion current as compared to the untreated specimen. Thin nitride layers which had the low concentration of TiN dendrites (sample 6), had structural defects such as pinholes or pores that directly exposed the base alloy to the environment and when titanium substrate was exposed to the aggressive medium, TiN acted as a cathode, induced anodic corrosion on the base metal and increased corrosion current.

The curves were typical of materials in the passive state with critical potentials. As the potential was scanned positively, the untreated alloy reached a passive region of $10^{-6} \mathrm{~A} / \mathrm{cm}^{2}$ current density. At approximately $600 \mathrm{mV}$, the current density started to increase again and reached a maximum at approximately $700 \mathrm{mV}$. This corresponds to the dissolution of the passive layer formed with the generation of another less passive region at approximately $900 \mathrm{mV}$. The proper laser nitrided sample (sample 11) exhibited a different behaviour. The increase of the current density was slower in the first passive region from the open circuit potential to approximately $1400 \mathrm{mV}$. The proper laser nitrited specimen exhibited less current density at $1400 \mathrm{mV}$, passivated more readily and also, maintained a lower current density over the duration of the experiment as shown from the slope of the potentiodynamic scans. This can be correlated with the formation of very thin, continuous $\operatorname{TiN}_{x} \mathrm{O}_{x}$ film in an oxidation state. However, elucidating the difference in corrosion mechanisms between Ti-6Al-4V alloy and laser gas nitrided Ti-6Al-4V alloy still needs further investigation.

As can be seen in Fig. 9, the sample 11 presented better behaviour than the sample 13. This was related to defects in nitrided layer and the relation between corrosion resistance and coating cracks. A difference between sample 11 and 13 was the great quality of the nitrided layer in sample 11, which was a deciding factor in protection of the base material. Therefore, high concentration of TiN dendrites, which induced crack initiation and propagation, reduced corrosion resistance of laser nitrided layer.

\subsubsection{Cyclic Polarization}

Figure 10 shows the cyclic polarization curves for the untreated and laser treated specimens. There were no signs of pitting for the untreated and proper laser nitrided samples (sample 11) because the reverse scans exhibited lower current density than the forward scans and showed no hysteresis. ${ }^{23)}$ This was due to the formation of continuous $\mathrm{TiO}_{2}$ and $\operatorname{TiN}_{\mathrm{x}} \mathrm{O}_{\mathrm{x}}$ passive layer on the untreated and proper laser nitrided specimens respectively. These passive layers could retard chloride ions ingress in to the material. However, samples with thin nitrided layer (sample 6) or with high TiN dendrite concentration and cracks (sample 13) showed lower pitting corrosion resistance. This was due to the fact that, TiN precipitates could serve as galvanic cathodes and accelerate the overall corrosion process. Also, chloride ions could penetrate to the base material through the surface layer defects. Pitting potential, $E_{\text {pit }}$, is the potential where passivity lost and current density increased suddenly. Once passivity has been lost, even at only discrete points on the surface, anodic polarization is controlled by the new reactions in the pits growing at those points. ${ }^{23)}$ For samples 6 and 13, after some degree of anodic polarization above $E_{\text {pit }}$, the direction of polarization is reversed and hysteresis is observed in which the return polarization curve follows an active path, compared to the initial anodic one. The crossover at the passive current density defines $E_{\text {pro }}$ below which established pits presumably cannot continue to grow. By contrast, new pits initiate only above $E_{\text {pit }}$. Between $E_{\text {pro }}$ and $E_{\text {pit }}$, new pits cannot initiate, but old ones can still grow. ${ }^{23-25)}$

\section{Conclusion}

(1) Laser gas nitriding of Ti-6Al-4V alloy by $\mathrm{Nd}$ :YAG pulsed laser produced a gold-colour surface consisted mainly of a thin continuous layer of titanium nitride followed by a nearly perpendicular dendrites, and below this, a mixture of small dendrites and large needles, which had a random orientation was produced.

(2) The denderitic structure was the TiN phase; the 

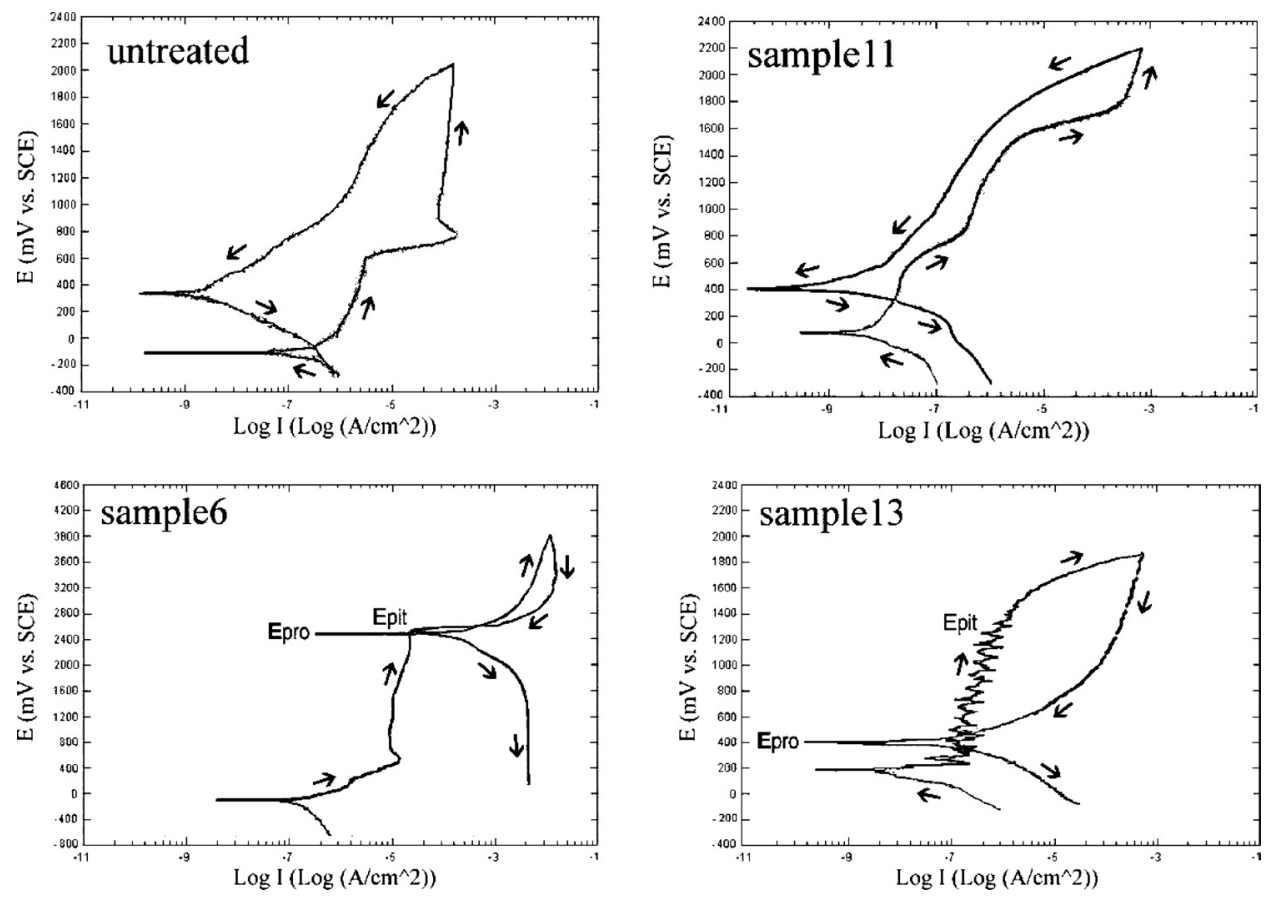

Fig. 10. Cyclic polarization curves for the untreated and laser treated specimens.

needle phase and the phase of the matrix between the dendrites were nitrogen-enriched $\alpha^{\prime}$-Ti. The density of TiN dendrites decreased gradually towards the interface between the nitrided layer and the substrate.

(3) Melt depth increased with an increase in energy input. The volume concentration and the sizes of the dendrites were also found to increase with increasing laser power and decreasing specimen velocity. Very high laser powers produced some vertical cracks passing through the melt depth. The melted zone showed a range of hardness of between $400-1300 \mathrm{Hv}$, the hardness being found to be related to the dendrite populations.

(4) The corrosion potential of laser gas nitrided specimens was relatively noble than the untreated sample and the proper laser treated specimen also had a very small corrosion current as compared to the untreated specimen. The proper laser nitrited surface was passivated more readily and also, maintained a lower current density over the duration of the experiment and there were no signs of pitting for these samples.

(5) By regulating the laser processing parameter, the microstructure of the nitrided layer could be controlled to optimize hardness and corrosion properties. This layer had a very pronounced hardness gradient along the melt depth direction, good metallurgical bonding to the substrate and excellent pitting corrosion resistance.

\section{Acknowledgments}

Authors would like to acknowledge Optics and Laser Research Center of Malek Ashtar University of Technology for the financial support and also wish to thank Dr. H. Saghafifar of Malek Ashtar University of Technology for his technical discussions.

\section{REFERENCES}

1) K. G. Budinski: Wear, 151 (1991), 203.
2) C. Hu, H. Xin, L. M. Watson and T. N. Baker: Acta Mater, 45 (1997), 4311.

3) V. M. Weerasinghe, D. R. F. West and J. de Damborenea: J. Mater. Process. Technol., 58 (1996), 79.

4) H. C. Man, N. Q. Zhao and Z. D. Cui: Surf. Coat. Technol., 192 (2005), 341.

5) P. Jiang, X. L. He, X. X. Li, L. G. Yu and H. M. Wang: Surf. Coat. Technol., 130 (2000), 24.

6) M. Ignatiev, E. kovalev and I. Melekhin: Wear, 166 (1993), 233.

7) S. Yerramareddy and S. Bahadur: Wear, 157 (1992), 245.

8) L. Jianglong, L. Qiquan and Z. Zhirong: Surf. Coat. Technol., 57 (1993), 191.

9) J. M. Robinson and R. C. Reed: Wear, 186-187 (1995), 360.

10) H. C. Man, Z. D. Cui, T. M. Yue and F. T. Cheng: Mater. Sci. Eng. A, A355 (2003), 167.

11) B. S. Yilbas, J. Nickel, A. Coban, M. Sami, S. Z. Shuja and A. Aleem: Wear, 212 (1997), 140.

12) B. S. Yilbas, M. S. J. Hashmi and S. Z. Shuja: Surf. Coat. Technol., 140 (2001), 244.

13) S. Mridha and T. N. Baker: J. Mater. Process. Technol., 77 (1998), 115.

14) B. S. Yilbas and M. S. J. Hashmi: J. Mater. Process. Technol., 103 (2000), 304.

15) C. Hu and T. N. Baker: Mater. Sci. Eng. A, A265 (1999), 268.

16) M. S. Selamat, T. N. Baker and L. M. Watson: J. Mater. Process. Technol., 113 (2001), 509.

17) T. M. Yue, T. M. Cheung and H. C. Man: J. Mater. Sci. Lett., 19 (2000), 205.

18) I. Garcia and J. J. de Damborenea: Corros. Sci., 40 (1998), 1411.

19) M. Khaled, B. S. Yilbas and J. Shirokoff: Surf. Coat. Technol., 148 (2001), 46.

20) T. M. Yue, J. K. Yu, Z. Mei and H. C. Man: Mater. Lett., 52 (2002), 206.

21) S. Mridha and T. N. Baker: Mater. Sci. Eng. A, A188 (1994), 229.

22) E. Gyorgy, A. P. del Pino, P. Serra and J. L. Morenza: Appl. Surf. Sci., 186 (2002), 130

23) D. A. Jones: Principles and Prevention of Corrosion, Prentice-Hall, NJ, USA, (1996), 218.

24) Corrosion, Metal/Environmental Reactions, Vol. 1, ed. by L. L. Shreir, R. A. Jarman and G. T. Burstein, Butterworth-Heinemann, Oxford, (1994), 179.

25) R. S. Razavi and T. Shahrabi: SAMPE2002 Symp. on Affordable Materials Technology, SAMPE, Long Beach, CA, (2002), 1722. 